\title{
Motor Developmental Delay
}

National Cancer Institute

\section{Source}

National Cancer Institute. Motor Developmental Delay. NCI Thesaurus. Code C116943.

Failure to meet, or late achievement of motor development milestones. 